\title{
Kinetics of Thermal Decomposition of Aqueous Perchloric Acid
}

\author{
M. Patricia Henderson, Viola I. Miasek, and T. W. Swaddle ${ }^{1}$ \\ Department of Chemistry, The University of Calgary, Calgary 44, Alberta
}

Received August 27, 1970

\begin{abstract}
Thermal decomposition of $1.1-6.6 \mathrm{~m}$ aqueous perchloric acid at $295-322^{\circ}$ yields oxygen, chlorine, and a small quantity of hydrochloric acid. The initial rates of decomposition have been measured, using a perchlorate ion activity electrode, and show 3.5 order dependence on the stoichiometric perchloric acid concentration; the corresponding rate coefficient and activation energy at $300.0^{\circ}$ are $3.1 \times 10^{-7} \mathrm{~m}^{-2.5} \mathrm{~s}^{-1}$ and $84 \mathrm{kcal} \mathrm{mole}^{-1}$, respectively. The order of reaction with respect to time is less than 3.5 and depends upon the initial perchloric acid concentration; this effect is due to acceleration of the decomposition by the reaction products, notably chloride ion. It is suggested that the ratedetermining step in the decomposition of aqueous perchloric acid is the reaction of two undissociated $\mathrm{HClO}_{4}$ molecules to give $\mathrm{H}_{2} \mathrm{O}, \mathrm{ClO}_{3}$, and $\mathrm{ClO}_{4}$.

Canadian Journal of Chemistry, 49, 317 (1971)
\end{abstract}

Perchloric acid is used extensively in physical studies of phenomena in aqueous solution, since it is the strongest of the common acids and also because its anion has remarkably little tendency to form complexes with metal ions. The aqueous acid is, however, thermodynamically unstable $\left(\Delta G^{0}=-26.3 \mathrm{kcal} / \mathrm{mole}^{-1}\right.$ at $25^{\circ}$ for the hypothetical $1 \mathrm{~m}$ solution (1)) with respect to decomposition to oxygen, chlorine, and water, and it is clear that the kinetics of this decomposition must be known if the acid is to be used in extending studies of aqueous electrolyte solutions to high temperatures.

Accordingly, the present study was designed primarily to provide empirical rate data on the decomposition of aqueous perchloric acid as a function of temperature, and over a concentration range which would include the commonlychosen "swamping electrolyte" values, 1-6 m. A literature search for such information was unsuccessful, although it has been reported (2) that no chlorine, $\mathrm{DOCl}, \mathrm{DClO}_{2}$, or $\mathrm{DClO}_{3}$ can be detected spectroscopically in $1 \mathrm{~m} \mathrm{DClO}_{4}$ after several days in a titanium vessel with sapphire windows at $250^{\circ}$. On the other hand, the decomposition of $83-100 \% \mathrm{HClO}_{4}$ has received considerable attention (3-8), as has the decomposition of $\mathrm{HClO}_{4}$ vapor $(9-12)$.

\section{Experimental}

All the stock chemicals used in this study were "Baker Analyzed" reagent grade, with the exception of ammonium nitrate (Matheson, Coleman and Bell) and sodium nitrate (Fisher Certified reagent). The perchloric acid $(72 \%)$ was used without further purification; the experi-

\footnotetext{
${ }^{1}$ To whom correspondence should be addressed.
}

mental results were independent of the manufacturer's batch. Lithium perchlorate trihydrate was made from lithium carbonate and perchloric acid. Distilled water was passed through Barnstead deionizer and organic removal cartridges before use. Red mercuric oxide was used as the primary standard in acidimetry. Spectrophotometric measurements were made using a Cary Model 15 spectrometer.

The pressure vessels used consisted of a cylindrical body $(2.54 \mathrm{~cm}$ i.d. $\times 4.60 \mathrm{~cm}$ o.d.) of ATL- $40 \mathrm{com}-$ mercially pure titanium, $0.2 \%$ palladium alloy (Atlas Titanium, Welland, Ontario), with a plug of the same material, such that the cavity volume was $62.0 \mathrm{~cm}^{3}$. The seal between plug and body was effected with a Teflon gasket contained between two $\mathrm{Ti}-0.2 \% \mathrm{Pd}$ rings, after the manner of Gill and Marshall (13). Retaining pressure was applied to the plug through a bearing ring which transmitted the thrust of six bolts located in the top of the externally-fitted stainless-steel screw cap.

The $\mathrm{T} i-0.2 \% \mathrm{Pd}$ alloy was selected because of its high resistance to attack by chlorine in the presence of water, together with its low susceptibility to crevice corrosion (which is a particularly serious hazard where Teflon gaskets are used and where chloride ion may be present) (14). However, it was found that $6 \mathrm{~m} \mathrm{HClO}_{4}$ attacked the metal appreciably at $300^{\circ}$, with the production of an orange solution containing titanium, evidently in the form of the familiar Ti(IV)-peroxy complexes. Accordingly, the vessels were fitted with silica liners with looselyfitting caps, for the purpose of kinetic studies involving $\mathrm{HClO}_{4}$ at high temperatures; attack of the titanium by the gaseous reaction products was then negligible except when chloride ion was added in large amounts to the $\mathrm{HClO}_{4}$, in which case very high chlorine pressures were developed and some $\mathrm{TiCl}_{4}$ fumes were observed on opening the vessels. The volume occupied by the silica liner and its cap was $14.2 \mathrm{~cm}^{3}$, and the capacity of the liner was about $30 \mathrm{ml}$.

Thermostating of the pressure vessels was achieved with a Blue M Conwate CW-160HF-1 forced-convection oven. The reaction temperature was measured with an iron-constantan thermocouple in conjunction with a Leeds-Northrup 742523-All potentiometer. A Thermoelectric Icell provided the cold-junction reference temperature $\left(0.00\right.$ to $\left.0.05^{\circ}\right)$, and the hot junction was en- 
closed in a thin-walled Pyrex sheath and immersed in Dow-Corning 560 silicone fluid contained in a dummy pressure vessel. The thermocouple was standardized frequently, either against a platinum resistance thermometer traceable to N.B.S., or against Fisher T-421 TherMetric fusion-point standards (notably anthraquinone, triple point $284.59 \pm 0.05^{\circ}$ )

With correct positioning of the pressure vessels in the oven and adequate stability of the room temperature, the reaction temperatures were constant within $\pm 0.2^{\circ}$ or better in the course of a kinetic experiment; where larger temperature uncertainties are stated, these reflect differences in the absolute value of the thermoregulator set-point from one set of experiments to another.

A Lauda NS-HT thermostat bath was used for calibrations against the platinum resistance thermometer, and for some experiments involving sampling of the gaseous reaction products. The latter employed the same pressure vessels but with the usual plug replaced by one having a long stem protruding $10 \mathrm{~cm}$ beyond the pressure vessel cap. This plug, of $\mathrm{Ti}-0.2 \% \mathrm{Pd}$ alloy, had a narrow axial bore which led to a stainless-steel high-pressure valve; the upper part of the plug stem extended out of the bath and was cooled with circulating water so as to protect the valve from corrosion. However, decomposition of the best available bath oils (Lauda Ultratherm 330S Circulating Fluid, and Dow Corning 560 Silicone Fluid) was so extensive when operating at $300^{\circ}$ that the NS-HT bath could be used only for a few brief experiments and calibrations.

In a typical kinetic run, $20.0 \mathrm{ml}$ aliquots of perchloric acid solution, of which both the hydrogen-ion and perchlorate contents had been measured, were placed in the silica liners, capped, and sealed in the pressure vessels under a nitrogen atmosphere. The vessels were placed in the overheated oven, so that the oven and vessel temperatures converged more rapidly upon the set-point. Thermal equilibrium was achieved in less than $50 \mathrm{~min}$ even at $322^{\circ}$, but the reaction time was reckoned from the time at which the monitored dummy vessel was within $5^{\circ}$ of the set-point (in effect, 35-40 min after insertion of the vessels). After a chosen reaction time, a vessel would be removed from the oven and chilled rapidly with cold water. The vessels were opened cautiously in the hood, the compressed gaseous products (chlorine and oxygen) being allowed to dissipate before removal of the screw-cap, and the contents of the liner and the condensate in the pressure vessel were transferred quantitatively to $50 \mathrm{ml}$ graduated flasks and made to the mark with water.

After dilution so that $0.01 \mathrm{M}<\left[\mathrm{ClO}_{4}{ }^{-}\right]<0.10 \mathrm{M}$, the ionic strength was adjusted to $1.0 \mathrm{M}$ with sodium nitrate, and the $\mathrm{p} H$ was made to about 5 with the minimum amount of concentrated $\mathrm{NaOH}$ solution, added with a syringe burette. The perchlorate ion concentration was then determined with an Orion 92-81 perchlorate ion activity electrode in conjunction with a Beckman Research Model $\mathrm{p} H$ Meter and an Orion 90-02 double junction reference electrode in which the outer chamber was filled with $10 \% \mathrm{NH}_{4} \mathrm{NO}_{3}$ solution.

The sample was thermostated $\left(20.5 \pm 0.1^{\circ}\right)$ and gently stirred magnetically while reading the electromotive force (e.m.f.); most of the dissolved chlorine escaped to the air, and in any event did not affect the electrode response. The e.m.f. reading was converted to perchlorate ion concentration using a calibration curve which had been set up in the same way with five standard $\mathrm{HClO}_{4}$ solutions spanning the range $0.01-0.10 \mathrm{M}$; plots of e.m.f. $v s$. $\log \left[\mathrm{ClO}_{4}{ }^{-}\right]$were invariably linear to a high degree, but a fresh calibration curve was necessary for each set of measurements. The stoichiometric perchlorate concentration so determined was accurate to $\pm 2.0 \%$ or better, but other factors such as leakage of gases during the kinetic runs could have introduced greater uncertainties. In general, triplicate kinetic measurements agreed to within $\pm 3.0 \%$. Concentrations were measured on the molar scale, for convenience, and subsequently converted (where possible) to the molal scale, using the density data of Markham (15) as adapted by Robertson (16).

Hydrogen ion concentrations were measured in a similar way, prior to $\mathrm{pH}$ adjustment, using a Beckman Futura 39311 glass electrode.

Potentiometric titration of perchlorate with tetraphenylarsonium chloride (17) was also tried, using the Gran method (18), but the procedure was no more accurate and much less convenient than the direct-reading method, and in any event standardization of the arsonium salt solution is necessary.

The chloride ion contents of some samples were determined using an $\mathrm{Ag} / \mathrm{AgCl}$ electrode, al though the residual chlorine in the solution affected the electrode response. Nevertheless, it was established that chloride ion was not a major reaction product; such $\mathrm{HCl}$ as was present in the solutions at $20^{\circ}$ probably came from reactions 1 and 2.

$$
\begin{aligned}
\mathrm{Cl}_{2}+\mathrm{H}_{2} \mathrm{O} & \rightleftharpoons \mathrm{HOCl}+\mathrm{H}^{+}+\mathrm{Cl}^{-} \\
2 \mathrm{HOCl} & \rightarrow 2 \mathrm{HCl}+\mathrm{O}_{2}
\end{aligned}
$$

Attempts were made to follow the decomposition of $\mathrm{HClO}_{4}$ by iodometric titration of the chlorine produced, but the reproducibility of the results was poor and the yields of chlorine were less than those expected on the basis of the corresponding perchlorate concentrations. These inconsistencies arose partly from the hydrolysis of chlorine to $\mathrm{HOCl}$ and $\mathrm{HCl}$, but mainly from leakage of gases from the reaction vessel on chilling, which often lead to gasket failure. There was no evidence of hightemperature leakage in any of the experiments referred to in this report.

\section{Reaction Products}

\section{Results}

The absence of chlorine gas, and the absence of a detectable increase in $\left[\mathrm{Cl}^{-}\right]$or a decrease in $\left[\mathrm{H}^{+}\right]$or $\left[\mathrm{ClO}_{4}{ }^{-}\right]$, showed that $4 \mathrm{~m} \mathrm{HClO}_{4}$ does not undergo significant thermal decomposition in $13 \mathrm{~h}$ at $250^{\circ}$; at $300^{\circ}$, however, much chlorine was produced in the same time. The absorption spectrum of the latter solution showed a pronounced maximum at $325 \mathrm{m \mu}$ which is characteristic of aqueous chlorine (19), but the absence of other features in this region of the 
spectrum indicated that $\mathrm{ClO}_{2}, \mathrm{ClO}_{2}^{-}$, and $\mathrm{HClO}_{2}$ were not present in significant amounts (20).

Chloride ion was present in the decomposed $\mathrm{HClO}_{4}$ solutions to the extent of $4 \%$ or less of the total chlorine in the decomposition products. This can be accounted for in terms of equilibrium 1 , which is rather rapidly established at room temperature and for which the equilibrium quotient is $4 \times 10^{-4} M^{2}$ at $25^{\circ}(21)$. Reaction 1 is endothermic $\left(\Delta H^{0}=5.06 \mathrm{kcal} \mathrm{mole}^{-1}\right)$ at $25^{\circ}$, but the data of Connick and Chia (21) suggest $\Delta C_{p}{ }^{0}=-95 \mathrm{cal} \mathrm{deg}^{-1} \mathrm{~mole}^{-1}$ at $25^{\circ}$, and, if this does not change greatly with temperature, it can be argued that equilibrium 1 will lie even further to the left at $300^{\circ}$. Thus, the chloride concentrations at $300^{\circ}$ will remain rather small, despite the high pressures of chlorine gas developed in $\mathrm{HClO}_{4}$ decompositions.

The direct vapor-phase hydrolysis of chlorine to $\mathrm{HCl}$ and oxygen is not favored thermodynamically at $300^{\circ}(22,23)$. However, $\mathrm{HCl}$ and $\mathrm{O}_{2}$ may be the main products of aqueous $\mathrm{HClO}_{4}$ decomposition at the critical temperature (24).

In the decomposition of pure aqueous $\mathrm{HClO}_{4}$, the decrease in perchlorate ion content to a stoichiometric concentration $c$ was invariably accompanied by a corresponding decrease in the hydrogen ion concentration to an amount exceeding $c$ but not greater than $1.06 c$. The slight excess of $\left[\mathrm{H}^{+}\right]$over $\left[\mathrm{ClO}_{4}{ }^{-}\right]$is evidently a consequence of reactions 1 and 2 , and it was therefore necessary to follow the progress of the decomposition of aqueous $\mathrm{HClO}_{4}$ by analyzing for the stoichiometric perchlorate concentration, $c$. It is, however, clear that the overall stoichiometry of decomposition is

[3] $4 \mathrm{H}^{+}+4 \mathrm{ClO}_{4}{ }^{-} \rightleftharpoons 2 \mathrm{H}_{2} \mathrm{O}+2 \mathrm{Cl}_{2}+7 \mathrm{O}_{2}$

Kinetics of Decomposition of Aqueous Perchloric Acid

Preliminary results obtained at $300^{\circ}$ showed that the apparent order of reaction with respect to time was dependent upon the initial concentration of $c_{0}$ of the perchloric acid. Thus, the perchlorate concentrations plotted against time in Fig. 1 refer to $c_{0}=6.61 \mathrm{~m}$ and require an order of 2.6 in stoichiometric perchloric acid with respect to time, while the corresponding order is 1.5 when $c_{0}=2.26 \mathrm{~m}$ (as is illustrated by the typical linear plot of $c^{-0.5} v s$. time in Fig. 2). Similarly, at $306^{\circ}$, the apparent order with re-

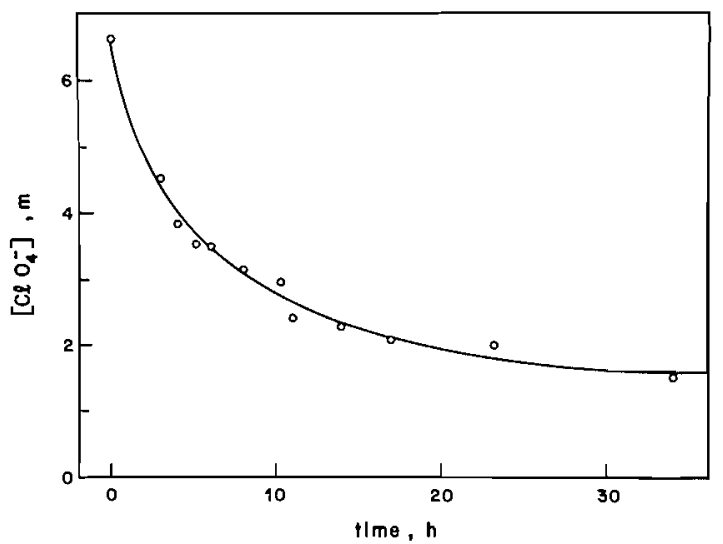

FIG. 1. Decomposition of $6.61 \mathrm{~m}$ perchloric acid at $300.0^{\circ}$

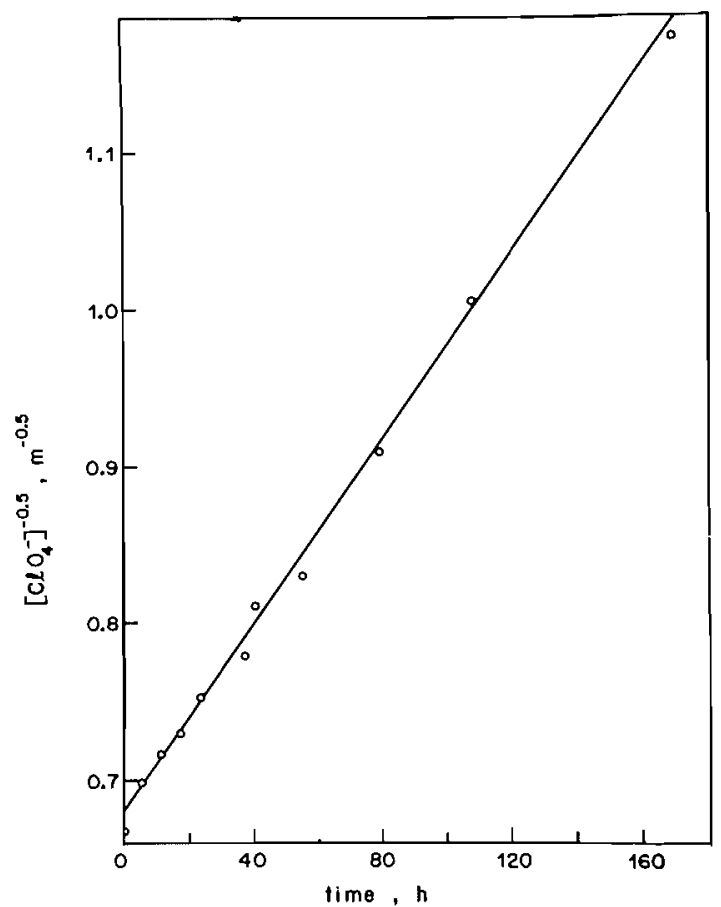

FIG. 2. Apparent 1.5-order kinetics of decomposition of $2.26 \mathrm{~m}$ perchloric acid at $300.0^{\circ}$.

spect to time was 2.0 for $c_{0}=3.60 \mathrm{~m}$, and at all temperatures studied the order was 1.5 when $c_{0}=2.26 \mathrm{~m}$. These apparent orders of reaction are purely empirical and do not necessarily have any theoretical significance; they do, however, represent the experimental data adequately to at least $80 \%$ completion of reaction. 
TABLE 1. Initial rates of decomposition of aqueous perchloric acid

\begin{tabular}{lcc}
\hline \hline & $\begin{array}{c}\text { Temperature } \\
c_{0}, m\end{array}$ & $\begin{array}{r}-\mathrm{d} c / \mathrm{d} t\left(\mathrm{~m} \mathrm{~s}^{-1}\right) \\
\text { as } c \rightarrow c_{0}\end{array}$ \\
\hline 6.61 & 300.0 & $2.2 \times 10^{-4}$ \\
5.06 & 300.0 & $8.7 \times 10^{-5}$ \\
3.59 & 300.0 & $2.3 \times 10^{-5}$ \\
2.26 & 300.0 & $5.6 \times 10^{-6}$ \\
1.09 & 300.0 & $5.3 \times 10^{-7}$ \\
4.63 & 306.5 & $1.7 \times 10^{-4}$ \\
3.60 & 306.0 & $5.1 \times 10^{-5}$ \\
2.26 & 306.0 & $9.8 \times 10^{-6}$ \\
1.02 & 306.5 & $1.1 \times 10^{-6}$ \\
\hline
\end{tabular}

These results are typical of reactions in which the products cause acceleration of the reaction rate $(25)$, and it is therefore necessary to determine the true order of the initial decomposition reaction (i.e., the order with respect to concentration) by graphical estimation of the initial rate of decomposition, $-\mathrm{d} c_{0} / \mathrm{d} t$, as a function of the initial perchloric acid concentration $c_{0}$. The estimation of initial rates is subject to rather large uncertainties, as will be obvious from Fig. 1 (this being a worse case than most), but log-log plots of the data of Table 1 show very clearly that the order of reaction is $3.50 \pm 0.05$, at 300 and $306^{\circ}$ at least

$$
-\mathrm{d} c / \mathrm{d} t=k_{3.5} c^{3.5}
$$

where $k_{3.5}$ has the weighted mean values of $3.1 \times 10^{-7} \mathrm{~m}^{-2.5} \mathrm{~s}^{-1}$ at $300^{\circ}$ and $5.7 \times 10^{-7}$ $m^{-2.5} \mathrm{~s}^{-1}$ at $306.0^{\circ}$, the error limits being $\pm 10 \%$ in either case.

In view of the difficulty of determining the initial rates of decomposition with sufficient accuracy from the sharply curved plots of $c$ vs. time, the activation energy $E$ was calculated using the apparent (1.5-order) rate coefficients for a fixed initial molality $(2.26 \mathrm{~m})$ of the acid. It is immaterial, for this purpose, that the apparent order with respect to time has no theoretical validity. We can write

$$
\text { [5] } \begin{aligned}
\ln \left(-\mathrm{d} c_{0} / \mathrm{d} t\right)=\ln k^{\prime}+n^{\prime} & \ln c_{0} \\
& =\ln k+n \ln c_{0}
\end{aligned}
$$

where $n$ and $n^{\prime}$ are the true and apparent reaction orders, and $k$ and $k^{\prime}$ are the corresponding rate coefficients, respectively. Then,

$$
\begin{aligned}
\ln k & =\left(n^{\prime}-n\right) \ln c_{0}+\ln k^{\prime} \\
& =\text { constant }+\ln k^{\prime}
\end{aligned}
$$

so that a plot of $\ln k^{\prime}$ against $1 / T$ will have the same slope as the Arrhenius plot for the true reaction order, so long as $n^{\prime}$ is independent of temperature and represents the data accurately.

Values of $k_{1.5}^{\prime}$ over a $27^{\circ}$ range of temperature are listed in Table 2. These, and all other data given in this article (except where otherwise stated), refer to $20.0 \mathrm{ml}$ samples with a gas space of $27.8 \mathrm{~cm}^{3}$ at $20^{\circ}$. Strictly speaking, a correction should be applied to the molalities measured at $20^{\circ}$ for water removed into the vapor phase at high temperatures. This cannot be done with great accuracy, since the vapor pressure of water in aqueous $\mathrm{HClO}_{4}$ at high temperatures is not accurately known, but we have assumed that it is the same fraction of the vapor pressure of pure water at high temperatures (26) as at $25^{\circ}(27)$ and we have calculated the increase $\Delta m$ in molality expected for $2.26 \mathrm{~m} \mathrm{HClO}_{4}$ at high temperatures, due allowance being made for the decrease in vapor volume brought about by expansion of the liquid phase (26). Estimates of $\Delta m$ are listed in column 3 of Table 2; it will be seen that $\Delta m$ is barely outside the experimental error, and accordingly we have chosen to ignore it except in column 4 of Table 2. The latter data show that the activation energy $E$ for the thermal decomposition of dilute aqueous perchloric acid is $84.2 \mathrm{kcal} \mathrm{mole}^{-1}$, with a possible uncertainty of $\pm 2 \mathrm{kcal} \mathrm{mole}^{-1}$. The $k_{1.5}^{\prime}$ data are reproduced by eq. 7 to within the experimental error

$$
\text { [7] } \log _{10} k_{1.5}^{\prime}=26.37-(18400 / T)
$$

The above analysis assumes that the decomposition of $\mathrm{HClO}_{4}$ occurs in the solution, and not the vapor, phase. This supposition was shown to be correct by partially decomposing 15,20 , and $25 \mathrm{ml}$ aliquots of $2.26 \mathrm{~m} \mathrm{HClO}_{4}$ at $306.0^{\circ}$ for identical periods of time. The vapor spaces in the three vessels would be $26.3,19.2$, and $12.0 \mathrm{~cm}^{3}$, and the relative rates of disappearance

TABLE 2. Apparent 1.5-order rate coefficients, $k_{1.5}$, for $c_{0}=2.26 \mathrm{~m}$

\begin{tabular}{cccc}
\hline $\begin{array}{c}\text { Temperature } \\
\left({ }^{\circ} \mathrm{C}\right)\end{array}$ & $\begin{array}{c}10^{6} k_{1.5^{\prime}} \\
\left(m^{-0.5} \mathrm{~s}^{-1}\right)\end{array}$ & $\Delta m(\%)$ & $\begin{array}{c}10^{6} k_{1} s^{\text {corr. }} \\
\left(m^{-0.5} \mathrm{~s}^{-1}\right)\end{array}$ \\
\hline $321.5 \pm 0.3$ & 26.2 & 4.3 & 25.7 \\
$312.3 \pm 0.2$ & 9.1 & 3.6 & 9.0 \\
$306.0 \pm 1.0$ & 4.41 & 3.5 & 4.3 \\
$304.3 \pm 0.2$ & $3.11_{4}$ & 3.4 & 3.09 \\
$300.0 \pm 1.0$ & 1.64 & 3.3 & 1.61 \\
$294.5 \pm 0.3$ & 0.87 & 3.2 & 0.86 \\
\hline
\end{tabular}


of $\mathrm{HClO}_{4}$ should therefore have been about 1.4:1.0:0.6 if decomposition of $\mathrm{HClO}_{4}$ vapor, in equilibrium with the dissolved acid, were the main contributor to the reaction rate (the negligible $\mathrm{HClO}_{4}$ content of the condensate formed outside the liner proved that most of the $\mathrm{HClO}_{4}$ remains in solution even at $322^{\circ}$ ). In fact, the reaction rates were rather similar and actually showed the opposite trend, if any at all (e.g., after $90.8 \mathrm{~h}$, the perchlorate concentrations remaining in the 20 and $25 \mathrm{ml}$ samples were 0.507 and $0.490 \mathrm{~m}$, respectively).

Addition of broken silica glass, such that the area of silica in contact with the solutions was more than doubled, produced no significant changes in the percentage decompositions per given time interval, within the experimental error. Thus, in $35.3 \mathrm{~h}$, at $306.0^{\circ}, 15 \mathrm{ml}$ of $2.26 \mathrm{~m}$ $\mathrm{HClO}_{4}$ decomposed to $1.26 \mathrm{~m}$ in the presence of about $5 \mathrm{ml}$ crushed silica, while the corresponding figure for $20 \mathrm{ml}$ of the same acid without added silica was $1.25 \mathrm{~m}$; similarly, after $73.0 \mathrm{~h}$, the corresponding data were 0.65 and $0.69 \mathrm{~m}$. It may therefore be concluded that the reaction is a homogeneous one, in solution.

Thus far, the reaction order has been expressed in terms of the stoichiometric $\mathrm{HClO}_{4}$ concentration; if the acid is completely dissociated, however, this order will represent the sum of the orders with respect to $\left[\mathrm{ClO}_{4}^{-}\right]$and $\left[\mathrm{H}^{+}\right]$. The reaction rate is directly proportional to the hydrogen-ion concentration raised to some power, since $2.26 \mathrm{~m} \mathrm{LiClO}_{4}$ underwent no decomposition (within the limits of detection) under conditions which brought about more than $50 \%$ decomposition of $2.26 \mathrm{~m} \mathrm{HClO}_{4}$.

The results of series of experiments at $300.0^{\circ}$ and roughly constant ionic strength $\left(\left[\mathrm{H}^{+}\right]+\right.$ $\left.\left[\mathrm{Li}^{+}\right]=\left[\mathrm{ClO}_{4}{ }^{-}\right]=2.2 \mathrm{~m}\right)$ are summarized in Table 3 in terms of extrapolated initial perchlorate decomposition rates. A plot of log $\left(-\mathrm{d} c_{0} / \mathrm{d} t\right)$ vs. $\log \left[\mathrm{H}^{+}\right]_{0}$ indicates an order of 1.2 (or $1.17 \pm 0.06$ ) with respect to hydrogen ion.

In order to check the order of reaction with respect to perchlorate ion directly, or to learn how the $\mathrm{HClO}_{4}$ decomposition rate responds to changes in the ionic strength, one must find an inert, non-basic, anionic substitute for perchlorate ion with a low tendency to ion-pairing, so that the ionic strength or the acidity can be maintained at will. Of the common anions, only the
TABLE 3. Initial rates of decomposition of $\mathrm{LiClO}_{4}$ $\mathrm{HClO}_{4}^{*}$ at $300.0^{\circ}$ as a function of initial hydrogen ion concentration, $\left[\mathrm{H}^{+}\right]_{0}$

\begin{tabular}{ccc}
\hline \hline$\left[\mathrm{H}^{+}\right]_{0}(m)$ & {$\left[\mathrm{ClO}_{4}{ }^{-}\right]_{0}(m)$} & $\begin{array}{c}10^{6} \times-\mathrm{d} c / \mathrm{d} t\left(m \mathrm{~s}^{-1}\right) \\
\text { at zero time }\end{array}$ \\
\hline 0.277 & 2.067 & 0.51 \\
0.555 & 2.167 & 1.19 \\
1.133 & 2.254 & 2.85 \\
2.256 & 2.256 & 5.5 \\
\hline
\end{tabular}

$*\left[\mathrm{H}^{+}\right]+\left[\mathrm{Li}^{+}\right]=\left[\mathrm{ClO}_{4}^{-}\right] \approx 2.2 \mathrm{~m}$.

hydrogen sulfate ion, $\mathrm{HSO}_{4}{ }^{-}$, behaves as a univalent, non-basic, non-acidic ion between 300 and $400^{\circ}(28)$, and a solution, $2 M$ in $\mathrm{LiClO}_{4}$ and $3 \mathrm{M}$ in $\mathrm{NaHSO}_{4}$ at $20^{\circ}$, showed no decomposition after $55 \mathrm{~h}$ at $294.5^{\circ}$.

The effect of added $\mathrm{NaHSO}_{4}$ on the rate of decomposition of $2 \mathrm{M}\left(20^{\circ}\right) \mathrm{HClO}_{4}$ is illustrated by the data of Table 4 , which show that a modest but definite "medium" or "ionic strength" effect causes the rate of $\mathrm{HClO}_{4}$ decomposition to decrease as the electrolyte concentration increases.

Semi-quantitative experiments, in which the extent of decomposition of $3.5 \mathrm{~m} \mathrm{HClO}_{4}$ at $300.0^{\circ}$ was compared with that of $2.26 \mathrm{~m} \mathrm{HClO}_{4} /$ $1.2 \mathrm{~m} \mathrm{H}^{\mathrm{H}}\left[\mathrm{HSO}_{4}\right]$ mixture, and $6.61 \mathrm{~m} \mathrm{HClO}_{4}$ with $2.26 \mathrm{~m} \mathrm{HClO}_{4} / 4.3 \mathrm{~m} \mathrm{H}\left[\mathrm{HSO}_{4}\right]$, confirmed that the true order of reaction with respect to perchlorate ion was roughly 2 at these concentrations of electrolytes.

When lithium chloride was added to the $\mathrm{HClO}_{4}$ before thermal decomposition, greatly increased yields of chlorine were obtained, and much $\mathrm{H}^{+}$and $\mathrm{Cl}^{-}$were consumed. The rate of loss of perchlorate was accelerated by the addition of moderate amounts of chloride. The decomposition of $2 \mathrm{M}\left(25^{\circ}\right) \mathrm{HClO}_{4}$ at $294.5^{\circ}$ in $23.3 \mathrm{~h}$ showed the same general features as the data for $55 \mathrm{~h}$ listed in Table 5 .

It should be noted, from Table 5, that the decrease $\Delta\left[\mathrm{H}^{+}\right]$in hydrogen-ion concentration equals the sum of $\Delta\left[\mathrm{ClO}_{4}^{-}\right]$and $\Delta\left[\mathrm{Cl}^{-}\right]$, within the experimental uncertainty. The apparent near-

TABLE 4. Effect of $3.0 \mathrm{M}\left(20^{\circ}\right) \mathrm{NaHSO}_{4}$ on the rate of decomposition of $2.05 M\left(20^{\circ}\right)$ perchloric acid at $294.5^{\circ}$

\begin{tabular}{|c|c|c|}
\hline $\begin{array}{l}\text { Elapsed } \\
\text { time (h) }\end{array}$ & $\begin{array}{c}\% \mathrm{ClO}_{4}^{-} \\
\text {decomposed, } \\
2 \mathrm{M} \mathrm{HClO}_{4}\end{array}$ & $\begin{array}{c}\% \mathrm{ClO}_{4}^{-} \text {decomposed, } \\
2 \mathrm{M} \mathrm{HClO}_{4} / 3 \mathrm{MNaHSO}_{4}\end{array}$ \\
\hline 55 & 23 & 20 \\
\hline 109 & 42 & 28 \\
\hline 165 & 47 & 33 \\
\hline
\end{tabular}


TABLE 5. Decomposition of $2 \mathrm{M} \mathrm{HClO}_{4}$ in $55 \mathrm{~h}$ in the presence of added $\mathrm{LiCl}$ at $294.5^{\circ}$ *

\begin{tabular}{ccccccccc}
\hline \hline$\left[\mathrm{H}^{+}\right]_{0}$ & {$\left[\mathrm{ClO}_{4}{ }^{-}\right]_{0}$} & {$\left[\mathrm{Cl}^{-}\right]_{0}$} & {$\left[\mathrm{H}^{+}\right]_{55}$} & {$\left[\mathrm{ClO}_{4}^{-}\right]_{55}$} & {$\left[\mathrm{Cl}^{-}\right]_{55}$} & $\Delta\left[\mathrm{H}^{+}\right]$ & $\Delta\left[\mathrm{ClO}_{4}^{-}\right]+\Delta\left[\mathrm{Cl}^{-}\right]$ & $\Delta\left[\mathrm{Cl}^{-}\right] / \Delta\left[\mathrm{ClO}_{4}{ }^{-}\right]$ \\
\hline 2.11 & 2.11 & 0.00 & 1.72 & 1.73 & 0.017 & 0.39 & 0.36 & - \\
2.08 & 2.08 & 0.56 & 1.10 & 1.56 & 0.034 & 0.98 & 1.05 & 1.0 \\
2.06 & 2.09 & 1.04 & 0.65 & 1.60 & 0.065 & 1.41 & 1.46 & 3.0 \\
2.13 & 2.04 & 1.63 & 0.26 & 1.57 & 0.220 & 1.87 & 1.88 & 3.0 \\
2.10 & 2.08 & 1.99 & 0.15 & 1.60 & 0.513 & 1.95 & 1.96 & 3.1 \\
2.11 & 2.08 & 4.03 & 0.08 & 1.59 & 2.505 & 2.03 & 2.01 &
\end{tabular}

*Concentrations are in $M$ units, determined experimentally at $20^{\circ}$; subscripts refer to time in hours.

constancy of $\Delta\left[\mathrm{ClO}_{4}{ }^{-}\right]$in the presence of added chloride is presumably fortuitous; acceleration by chloride is evidently compensated for by reductions in the reaction rate caused by the rapid exhaustion of the hydrogen ion content. The effect of chloride ion requires the presence of hydrogen ion, since it was found that $2 M$ $\left(25^{\circ}\right) \mathrm{LiClO}_{4}$ containing $2 \mathrm{M}\left(25^{\circ}\right) \mathrm{LiCl}$ underwent no detectable loss of perchlorate or evolution of chlorine in $55 \mathrm{~h}$ at $294.5^{\circ}$.

\section{Discussion}

The initial rate of decomposition of dilute aqueous $\mathrm{HClO}_{4}$ decreases approximately threefold for each $10^{\circ}$ decrease in temperature, and approximately ten-fold for each halving of the initial concentration of $\mathrm{HClO}_{4}$. These large effects are reflections of the unusually high activation energy ( $84 \mathrm{kcal} \mathrm{mole}^{-1}$ ) and order of reaction (3.5) with respect to the substrate. Since the initial rate of decomposition of $1 \mathrm{~m} \mathrm{HClO}_{4}$ is small $\left(5 \times 10^{-7} \mathrm{~m} \mathrm{~s}^{-1}\right)$ at $300^{\circ}$, it can be stated that the rate is negligibly small for $1 \mathrm{~m} \mathrm{HClO}_{4}$ at $250^{\circ}$ and for the $0.2 \mathrm{~m}$ acid at $300^{\circ}$, as far as experiments of about a day's duration are concerned. Perchloric acid may therefore have considerable utility in physico-chemical studies of high temperature aqueous solutions, although direct attack by $\mathrm{HClO}_{4}$ on oxidizable solute species such as transition-metal ions may limit its applicability.

The observed non-integral orders of reaction with respect to hydrogen ion (about 1.2) and perchlorate ion (by difference, about 2.3) prevent the unambiguous assignment of a reaction mechanism. The reaction was found to be somewhat retarded by high concentrations of inert electrolyte $\left(\mathrm{NaHSO}_{4}\right)$, and so the overall molecularity of reaction with respect to the stoichiometric $\mathrm{HClO}_{4}$ concentration is probably 4 . The orders of reaction with respect to $\mathrm{H}^{+}$and $\mathrm{ClO}_{4}{ }^{-}$ separately are each greater than 1 , and it is probable that the molecularity is 2 with respect to each of these species. The "ionic strength" concept, used in deriving the order in $\mathrm{H}^{+}$, may not be reliable at these high temperatures, at which the product of the solvent dielectric constant and the absolute temperature has less than half its room temperature value; this is particularly unsatisfactory since the substrate $\left(\mathrm{HClO}_{4}\right)$ comprised most or all of the electrolyte present in many of the experiments. There is also the possibility that the perchloric acid is appreciably associated near $300^{\circ}$.

However, if we assume that the molecularities with respect to $\mathrm{H}^{+}$and $\mathrm{ClO}_{4}{ }^{-}$are both 2 , then the stoichiometric mechanism is probably

$$
\begin{aligned}
& \text { [8] } \mathrm{H}^{+}+\mathrm{ClO}_{4}^{-} \stackrel{K}{\rightleftharpoons} \mathrm{HClO}_{4} \\
& \text { [9] } 2 \mathrm{HClO}_{4} \stackrel{\text { slow }}{\longrightarrow} \text { intermediates } \\
& \stackrel{\text { fast }}{\longrightarrow} \mathrm{H}_{2} \mathrm{O}+\mathrm{Cl}_{2}+\frac{7}{2} \mathrm{O}_{2}
\end{aligned}
$$

Values of the association constant $K$ of $\mathrm{HClO}_{4}$ are not accurately known even for temperatures below $100^{\circ}$; the available estimates are conflicting $(27,29)$, but it seems that not more than $1 \%$ of the $\mathrm{HClO}_{4}$ in the solutions used in the present study could be associated at $25^{\circ}$. Reaction 8 is likely to be endothermic with a positive molal heat capacity change, so that association could be extensive in the temperature range of interest (295-322 $)$. However, for the much weaker acid $\mathrm{HCl}, K$ is only about $30 \mathrm{~m}^{-1}$ at $306^{\circ}(30)$, while sulfuric acid (which, as $\mathrm{H}\left[\mathrm{HSO}_{4}\right]$, is a close analogue of $\mathrm{H}\left[\mathrm{ClO}_{4}\right]$ ) is recognized (28) to behave as a strong uni-univalent electrolyte between 300 and $400^{\circ}$. It therefore seems reasonable to assume that only a small fraction of the $\mathrm{HClO}_{4}$ is associated at $295-322^{\circ}$, so that the mechanism of reactions 8 and 9 would give rise to a fourth-order rate law. 
The nature of reaction 9 is a matter for speculation, since we detected no intermediates. The reversible condensation of two $\mathrm{HClO}_{4}$ molecules to give water and the relatively unstable anhydride $\mathrm{Cl}_{2} \mathrm{O}_{7}$ has been suggested $(3,4,6,7)$ for the decomposition of $83-100 \% \mathrm{HClO}_{4}$, but Pearson (31) considers this improbable, and besides it is scarcely likely to be relevant to dilute aqueous $\mathrm{HClO}_{4}$.

The rate of homogeneous pyrolysis of $\mathrm{HClO}_{4}$ vapor is first order in molecular $\mathrm{HClO}_{4}$, and has an activation energy of $45.1 \mathrm{kcal} \mathrm{mole}^{-1}$, which is close to the $\mathrm{HO}-\mathrm{ClO}_{3}$ bond energy of $48.3 \mathrm{kcal} \mathrm{mole}^{-1}(9)$; in contrast, the $\mathrm{H}-\mathrm{OClO}_{3}$ bond energy is $112 \mathrm{kcal} \mathrm{mole}^{-1}(32)$, and the $\mathrm{O}-\mathrm{ClO}_{3} \mathrm{H}$ energy is over $105 \mathrm{kcal} \mathrm{mole}^{-1}$ (5). It is therefore highly probable that reaction 10 is the rate-determining step in the homogeneous gas-phase pyrolysis of $\mathrm{HClO}_{4}$.

$$
\mathrm{HClO}_{4} \rightarrow \mathrm{HO}+\mathrm{ClO}_{3}
$$

This is supported by Fisher's demonstration (11) that $\mathrm{ClO}$ is a major reaction intermediate, along with some $\mathrm{ClO}_{2}$; these probably originate from $\mathrm{ClO}_{3}$ and $\mathrm{ClO}_{4}$. The rapid reactions following [10] are probably [11] through [16].

$$
\begin{aligned}
\mathrm{HClO}_{4}+\mathrm{OH} & \rightarrow \mathrm{H}_{2} \mathrm{O}+\mathrm{ClO}_{4} \cdot \\
\mathrm{ClO}_{4} \cdot & \rightarrow \mathrm{ClO}_{2}+\mathrm{O}_{2} \\
\mathrm{ClO}_{2} & \rightarrow \mathrm{Cl}^{\cdot}+\mathrm{O}_{2} \\
2 \mathrm{Cl} \cdot & \rightarrow \mathrm{Cl}_{2} \\
\cdot \mathrm{ClO}_{3} & \rightarrow{ }^{\cdot} \mathrm{ClO}+\mathrm{O}_{2} \\
2 \cdot \mathrm{ClO} & \rightarrow \mathrm{Cl}_{2}+\mathrm{O}_{2}
\end{aligned}
$$

In contrast to the gas-phase reaction, the decomposition of dilute aqueous $\mathrm{HClO}_{4}$ appears to be bimolecular in undissociated $\mathrm{HClO}_{4}$, and we therefore propose that the rate-determining step in solution involves association of two $\mathrm{HClO}_{4}$ molecules through interaction of their strong $-\mathrm{O}^{\delta-} \mathrm{H}^{\delta+}$ dipoles. The resulting geometry will be favorable to the elimination of $\mathrm{H}_{2} \mathrm{O}$ and the formation of the fragments ${ }^{\circ} \mathrm{ClO}_{3}$ and ${ }^{\circ} \mathrm{ClO}_{4}$ (reaction 17) which would subsequently decompose rapidly to oxygen and chlorine via reactions 12 through 16.

$[17] \mathrm{O}_{3} \mathrm{Cl}-\mathrm{OH}+\mathrm{H}-\mathrm{OClO}_{3} \stackrel{\text { slow }}{\longrightarrow} \mathrm{ClO}_{4} \cdot+\mathrm{ClO}_{3}+\mathrm{H}_{2} \mathrm{O}$

It will be seen that this is the same as the probable gas-phase mechanism outlined above, except that the sequential reactions 10 and 11 have coalesced into a single synchronous step. It also resembles the condensation mechanism favored by Zinoviev et al. $(3,4,6,7)$, except that independent $\mathrm{ClO}_{3}$ and $\mathrm{ClO}_{4}$ fragments are the products of the initial step, rather than $\mathrm{Cl}_{2} \mathrm{O}_{7}$.

If the $\mathrm{H}-\mathrm{OH}$ bond energy is taken to be 117 kcal mole ${ }^{-1}$, then the minimal activation energy for step 17 in the gas phase is $43 \mathrm{kcal} \mathrm{mole}^{-1}$; in solution, the polar molecule $\mathrm{HClO}_{4}$ would be further stabilized relative to the products of step 17 , so that the activation energy for this step may be $50 \mathrm{kcal} \mathrm{mole}^{-1}$ or more. The enthalpy change of reaction 8 at about $300^{\circ}$ can only be guessed at, but it will almost certainly be quite endothermic, and, by analogy with $\mathrm{HCl}$ (for which $\Delta H^{0}$ is about $17 \mathrm{kcal} \mathrm{mole}^{-1}$ (30) for association of the aqueous acid), we can anticipate that $10<\Delta H^{0}<25 \mathrm{kcal} \mathrm{mole}^{-1}$. Hence, for a mechanism in which reaction 8 (taken twice) is followed by the rate-determining step 17 , we can expect an overall activation energy greater than 70 and perhaps as much as $100 \mathrm{kcal}$ mole ${ }^{-1}$; the observed value is $84 \mathrm{kcal} \mathrm{mole}^{-1}$.

The addition of chloride ion to aqueous perchloric acid must reduce the free $\mathrm{H}^{+}$concentration at high temperatures by forming molecular $\mathrm{HCl}(30)$, yet it is observed that the decomposition of $\mathrm{HClO}_{4}$ is actually faster when chloride is added. Evidently, a direct reaction can occur between $\mathrm{HCl}$ and $\mathrm{ClO}_{4}{ }^{-}$(or possibly $\mathrm{HClO}_{4}$ ). The data of Table 5 show that, if enough chloride is present, three moles of chloride are consumed for each mole of perchlorate decomposed. The stoichiometry of the chloride-dependent pathway is therefore,

[18] $4 \mathrm{H}^{+}+3 \mathrm{Cl}^{-}+\mathrm{ClO}_{4}^{-}=2 \mathrm{Cl}_{2}+2 \mathrm{H}_{2} \mathrm{O}+\mathrm{O}_{2}$

It will be noted that, regardless of what fraction of the decomposition goes by reaction 18 , the change in hydrogen ion concentration, $\Delta\left[\mathrm{H}^{+}\right]$, is given by eq. 19 , which is verified by the data of Table 5 .

\section{[19]

$$
\Delta\left[\mathrm{H}^{+}\right]=\Delta\left[\mathrm{Cl}^{-}\right]+\Delta\left[\mathrm{ClO}_{4}^{-}\right]
$$

Reaction 18 is best accounted for by the mechanistic sequence [20]-[23], which, like the gas-phase pyrolysis scheme of Fisher (11), involves the rapid decomposition of $\mathrm{ClO}_{3}$ to $\mathrm{ClO}$ and oxygen. Other plausible mechanisms which do not involve this step give the wrong overall stoichiometry. Reaction 23 will be complex. 


$$
\begin{aligned}
& {[20] \mathrm{H}^{+}+\mathrm{HCl}+\mathrm{ClO}_{4}-\stackrel{\text { slow }}{\longrightarrow} \mathrm{Cl}^{\cdot}+\mathrm{H}_{2} \mathrm{O}+\mathrm{ClO}_{3}} \\
& 2 \mathrm{Cl} \stackrel{\text { fast }}{\longrightarrow} \mathrm{Cl}_{2} \\
& \mathrm{ClO}_{3} \stackrel{\text { fast }}{\longrightarrow} \mathrm{ClO}^{\cdot}+\mathrm{O}_{2} \\
& \mathrm{ClO}+2 \mathrm{HCl} \stackrel{\text { fast }}{\longrightarrow} \mathrm{H}_{2} \mathrm{O}+\frac{3}{2} \mathrm{Cl}_{2}
\end{aligned}
$$

The observed acceleration of the decomposition of pure aqueous $\mathrm{HClO}_{4}$ by its own decomposition products (specifically $\mathrm{Cl}_{2}$ ) can be attributed, at least in part, to the production of small amounts of chloride by reactions 1 and 2. It might be noted that bromide (33) and iodide (34) ions both can cause reduction of aqueous $\mathrm{HClO}_{4}$ at temperatures as low as 100 $135^{\circ}$.

We thank Dr. J. M. Simmie for the mass spectra, and Drs. P. W. M. Jacobs and W. E. Jones for supplying copies of otherwise unobtainable articles. We are grateful to the National Research Council of Canada for an operating grant.

1. D. D. Wagman, W. H. Evans, V. B. Parker, I. Halow, S. M. BaIley, and R. H. Schumm. Selected Values of Chemical Thermodynamic Properties. N.B.S. Technical Note 270-3, Washington, D.C., 1968.

2. W. C. WAGGENER, A. J. WeINBERGER, and R. W. Stoughton. Appl. Spectrosc. 22, 545 (1968).

3. A. E. Missan and A. M. SukHotin. Russ. J. Inorg. Chem. 4, 276 (1959).

4. A. A. ZINoviev and A. B. TsentsiPer. Russ. J. Inorg. Chem. 4, 329 (1959).

5. A. B. Tsentsiper. Russ. J. Inorg. Chem. 4, 493 (1959).

6. A. A. Zinoviev and V. P. Babaeva. Russ. J. Inorg. Chem. 6, 138 (1961).

7. V. P. Babaeva and A. A. Zinoviev. Russ. J. Inorg. Chem. 8, 288 (1963).

8. V. P. Babaeva and A. A. Zinoviev. Dokl. Akad. Nauk SSSR, 149, 592 (1963).

9. J. B, LEVY, J. Phys. Chem. 66, 1092 (1963).

10. D. J. SibbetT and J. M. Lobato. Investigation of the Mechanism of Combustion of Composite Solid Propellants. Aerojet Report No. 1782, AerojetGeneral Corp., Azusa, California, April 1960.
11. I. P. Fisher. A Mass Spectrometric Study of the Thermal Decomposition of Perchloric Acid and Chlorine Dioxide. Technical Report No. 66/13, Rocket Propulsion Establishment, Westcott, England, November 1966; Trans. Faraday Soc. 63, 684 (1967).

12. G. A. Heath and J. R. MaJer. Trans. Faraday Soc. 60, 1783 (1964).

13. J. S. Gill and W. L. Marshall. Rev. Sci. Instr. 32, 1060 (1961).

14. Titanium Design Data Book for the Chemical Processor. Titanium Metals Corp. of America, 233 Broadway, New York, N.Y. pp. 13, 23, 64.

15. A. E. Markham. J. Amer. Chem. Soc. 63, 874 (1941).

16. E. B. Robertson. Ph.D. Thesis. University of Alberta, Edmonton, Alberta. 1964.

17. R. J. Baczuk and R. J. DuBors. Anal. Chem. 40 , 685 (1968).

18. A. Liberto and M. Mascini. Anal. Chem. 41, 676 (1969).

19. W. C. Fergusson, L. Slotin, and D. W. G. Styles. Trans. Faraday Soc. 32, 956 (1936).

20. C. C. Hong and W. H. Rapson. Can. J. Chem. 46, 2061 (1968).

21. R. E. ConNick and Y.-T. Chia, J. Amer. Chem. Soc. 81, 1280 (1959).

22. A. E. Korvezee. Rec. Trav. Chim. Pays-Bas, 50, 1092 (1931).

23. A. R. Gordon and C. Barnes. J. Phys. Chem. 36, 2292 (1932).

24. E. V. JONES and W. L. MARShall. Reactor Chemistry Division Annual Report ORNL-4229-UC-4, Oak Ridge National Laboratory, Oak Ridge, Tennessee. 1967. p. 90.

25. K. J. LaIDler. Reaction Kinetics. Vol. 1. Pergamon Press, Oxford, England. 1963. pp. 18-19.

26. N. E. DoRsEY. Properties of Ordinary Water-Substance. Reinhold Publishing Corp., New York, N.Y. 1940.

27. R. HAASE, K.-H. DüCKer, and H. A. KüPPERS. Ber. Bunsenges. Phys. Chem. 69, 97 (1965).

28. A. S. Quist, W. L. Marshall, and H. R. Jolley. J. Phys. Chem. 69, 2726 (1965).

29. J. W. AkITt, A. K. Covington, J. G. Freeman, and T. H. LILley. Trans. Faraday Soc. 65, 2701 (1969).

30. A. E. Martell and L.-G. SilléN. Stability Constants. Chemical Society Special Publication No. 17, London, 1964. p. 272.

31. G. S. Pearson. Advan. Inorg. Radiochem. 8, 177 (1966).

32. I. P. FIsHeR. Trans. Faraday Soc. 64, 1852 (1968).

33. W. R. Crowell, D. M. Yost, and J. D. Roberts. J. Amer. Chem. Soc. 62, 2176 (1940).

34. E. Kahane and T. Tomesco. Compt. Rend. 201, 1195 (1935). 